\title{
Recent investigations of the south Indian Middle Palaeolithic: the Middle Godavari basin
}

\author{
Mokshada Salunke*
}

This article focuses on the Middle Palaeolithic of a region of south India, highlighting diverse stratigraphic contexts and lithic reduction sequences suggestive of high mobility and planning in raw material usage.

Keywords: India, Godavari, Middle Palaeolithic, blade technology

The origins and development of the Middle Palaeolithic in India are particularly important in the context of debates about the dispersals of modern humans, i.e. the 'Out-of-Africa' movement (Bae et al. 2017; Hublin et al. 2017; Brooks et al. 2018). Studies show that transitional processes from the Late Acheulian leading to the Indian Middle Palaeolithic began as early as between $385 \pm 64 \mathrm{ka}$ and $172 \pm 41 \mathrm{ka}$ (Akhilesh et al. 2018), and continued after the Toba volcanic event at $\sim 74 \mathrm{ka}$ (Petraglia et al. 2007). It was succeeded by the Late Palaeolithic/microlithic assemblages of India, the earliest dates for which are $\sim 46 \mathrm{ka}$ (Mishra et al. 2013). The Indian Middle Palaeolithic is characterised by small flake tools, the continued production of bifaces, often of small size, and the presence of the Levallois and blade reduction sequences, with preferences for fine-grained quartzites and other siliceous materials (Blinkhorn \& Petraglia 2017; Akhilesh et al. 2018). A general lack of studies, however, hampers our knowledge of the Middle Palaeolithic in India.

The Middle Godavari basin, south India, is rich in Acheulian, Middle and Upper Palaeolithic sites (see Singh 1984), and is therefore an important region for the investigation of cultural adaptations and evolution, as well as for investigating the timing and nature of population dispersals into and across South Asia. Building on a long history of research in this region, recent debates about the Indian Middle Palaeolithic have prompted new investigations (Blinkhorn \& Petraglia 2017; Akhilesh et al. 2018). In a recent survey $\left(6491 \mathrm{~km}^{2}\right)$, two Acheulian, six Middle Palaeolithic and 13 Late Palaeolithic sites were chosen to study (Figure 1). Here, we focus on the Middle Palaeolithic (six sites, 1302 lithic artefacts). The sites are located primarily in areas marked by Lower Gondwana formations (Geological Survey of India 2002). They occur as surface scatters eroding from sediments overlying bedrock (Figure 2). These comprise debris flows associated with calcareous sediments (Figure 3), regoliths derived from weathered bedrock, and strath gravels and fluvial gravels (Figure 4).

\footnotetext{
* Deccan College Post-Graduate and Research Institute, Yerwada, Pune-411006, Maharashtra, India (Email: moksh.salunke@gmail.com)
} 


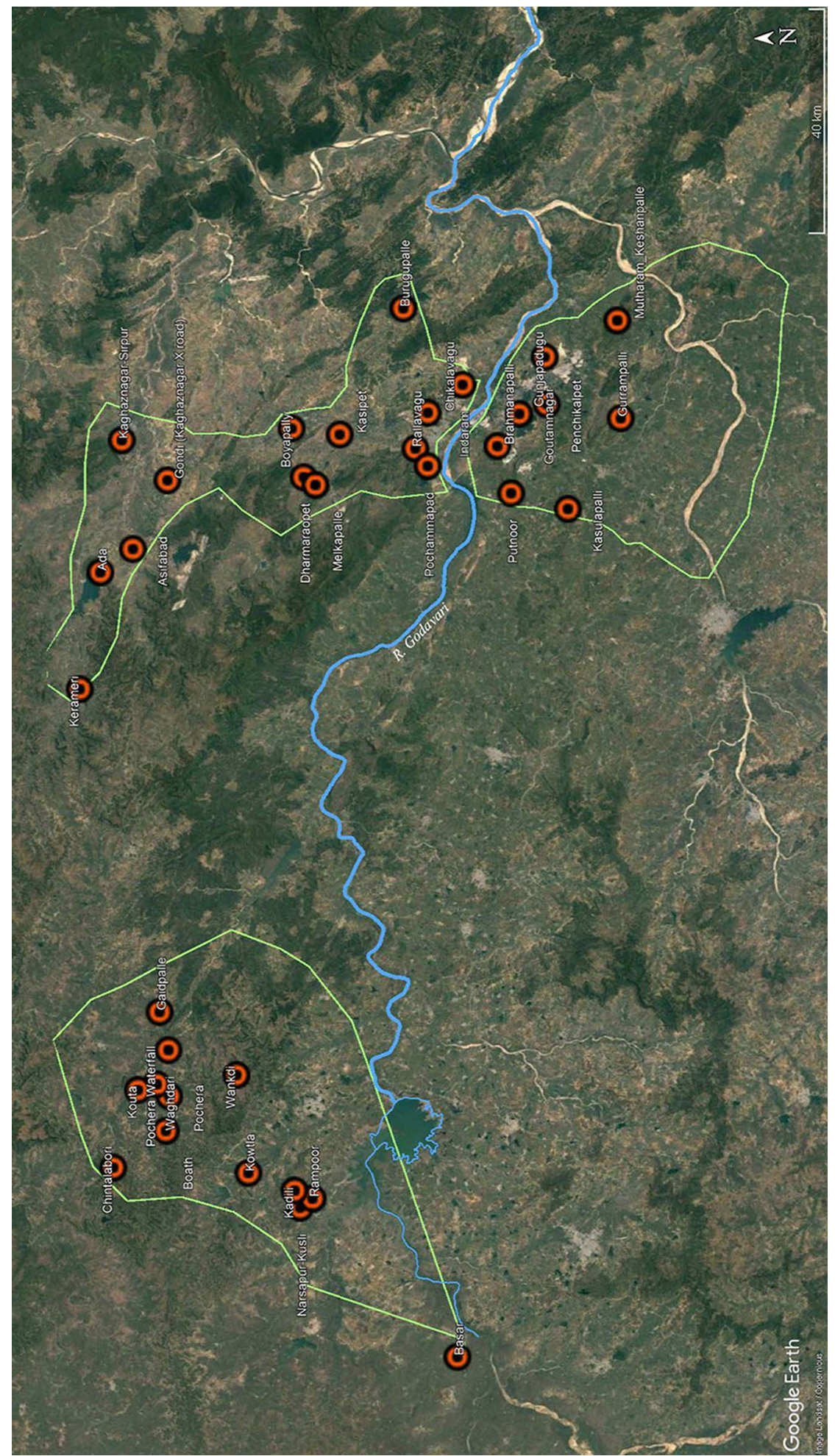

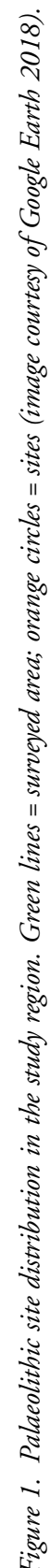

(C) Antiquity Publications Ltd, 2018 
Recent investigations of the south Indian Middle Palaeolithic
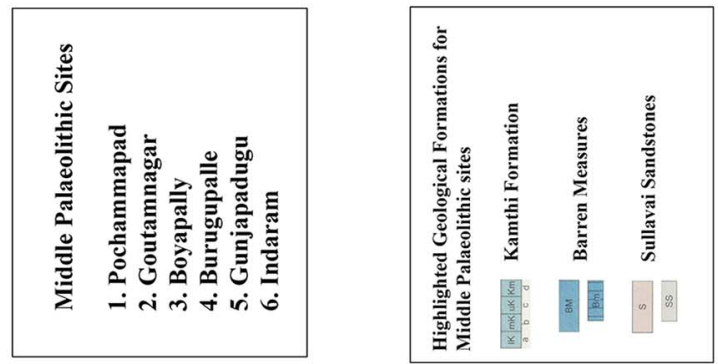

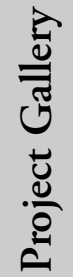

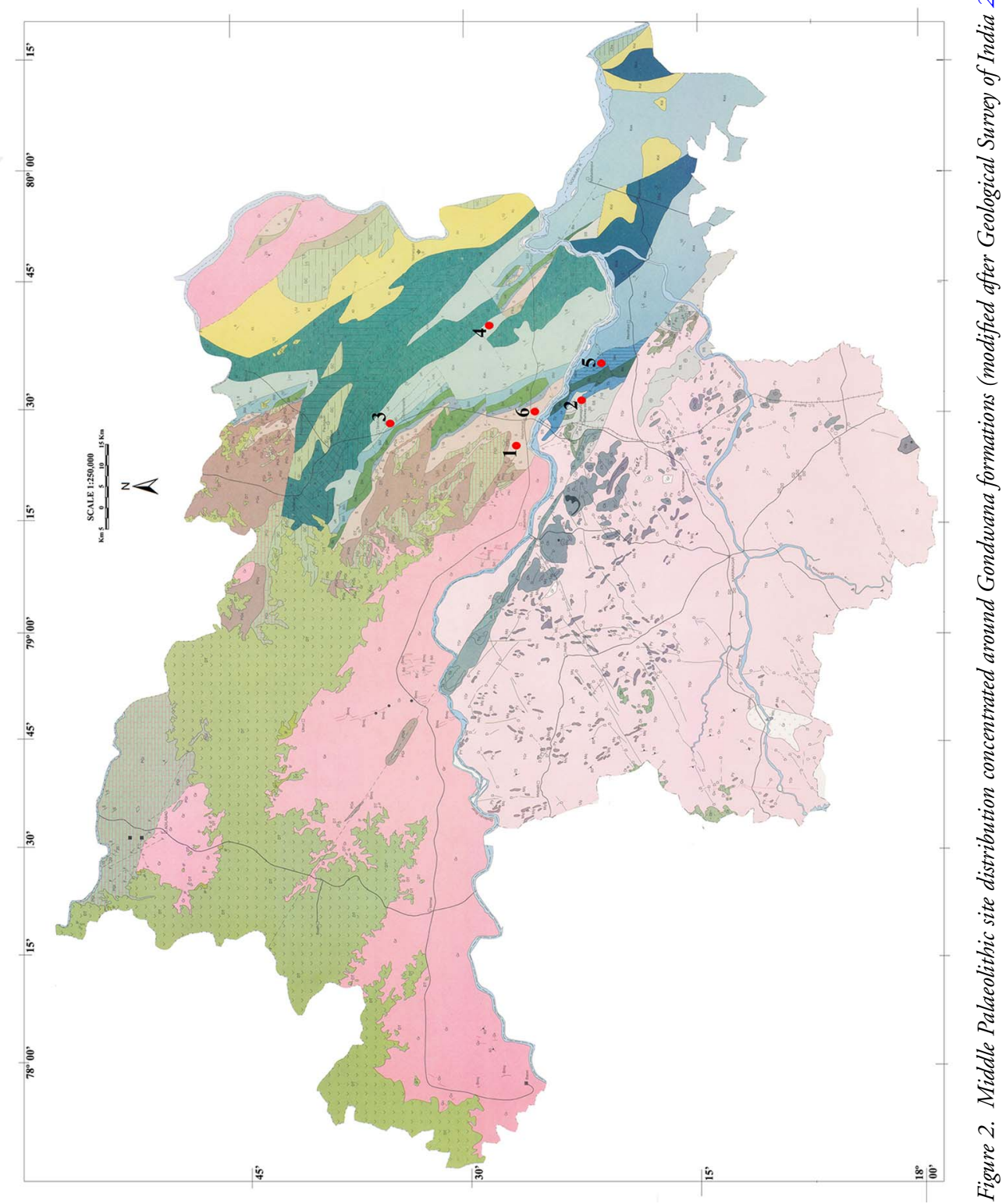

(C) Antiquity Publications Ltd, 2018 


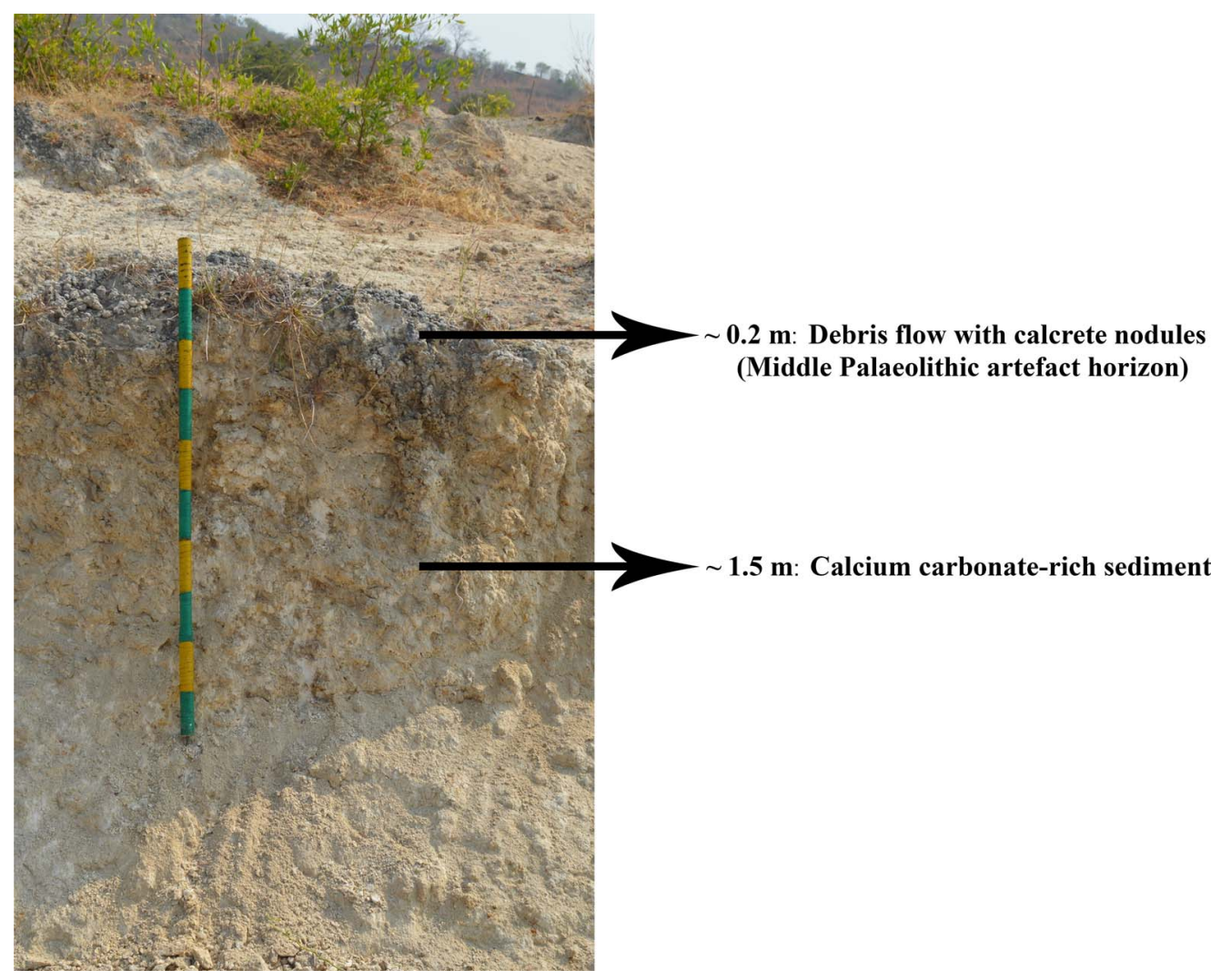

Figure 3. Section (site: Pochammapad) showing the context of Middle Palaeolithic artefacts associated with debris flow overlying calcareous sediments $($ scale $=1 \mathrm{~m})$.

The artefacts recovered are fresh and unabraded, comprising cores, tools and waste products (mean dimensions of all artefacts are $48.61 \times 40.11 \times 18.44 \mathrm{~mm}$ ). The presence of waste flakes (less than $20 \mathrm{~mm}$ in size) at three of the sites is indicative of high site integrity with minimal fluvial or other disturbances (Schick 1992). Quartzites dominate the assemblage (86.10 per cent), with a few artefacts of chert (12.21 per cent), chalcedony and quartz. Quartzites are inferred to derive from the Talchir boulder beds roughly $\sim 80 \mathrm{~km}$ from the sites (Geological Survey of India 2002), and thus are non-local; further investigations on this are in progress. Flake cores $(n=151)$ are generally on quartzite cobbles. Prepared cores $(n=61)$ include preferential and recurrent Levallois $(\mathrm{n}=3)$ (Figure 5) and discoidal cores $(\mathrm{n}=2)$, among other variants. Other flake cores include laminar cores $(\mathrm{n}=18)$ and multidirectional flake cores $(n=11)$. The tools $(n=560)$ are predominantly scrapers and notches, with a few small handaxes and cleavers. Most tools are on flakes, including a few on Levallois blanks. Cortex is generally less than 50 per cent. 


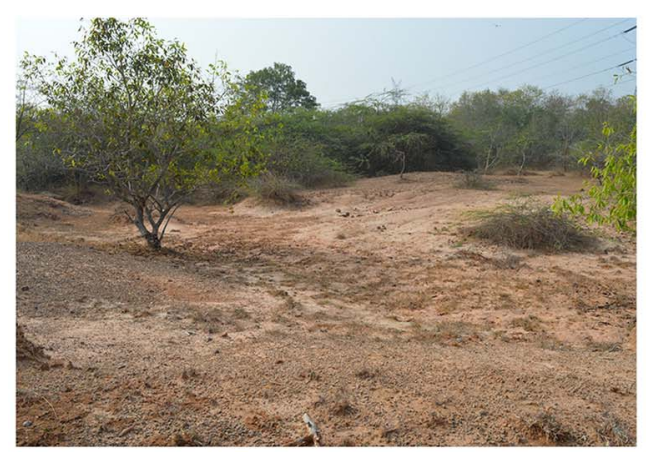

(a)

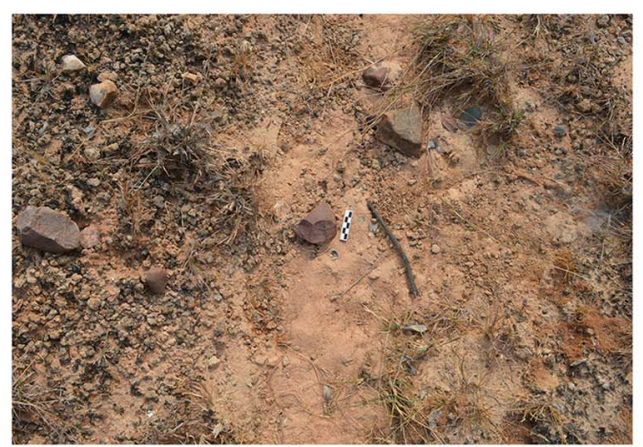

(c)

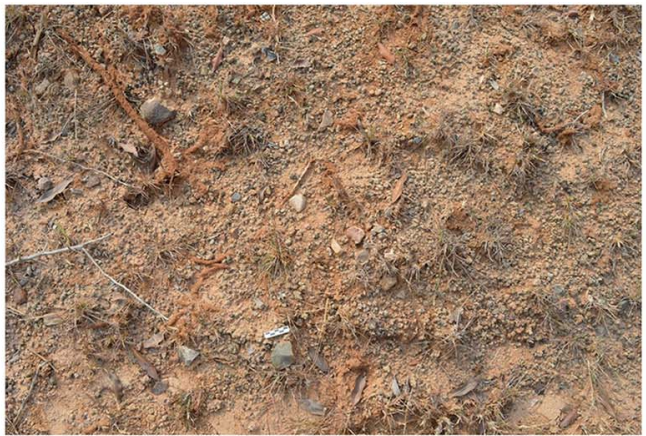

(b)

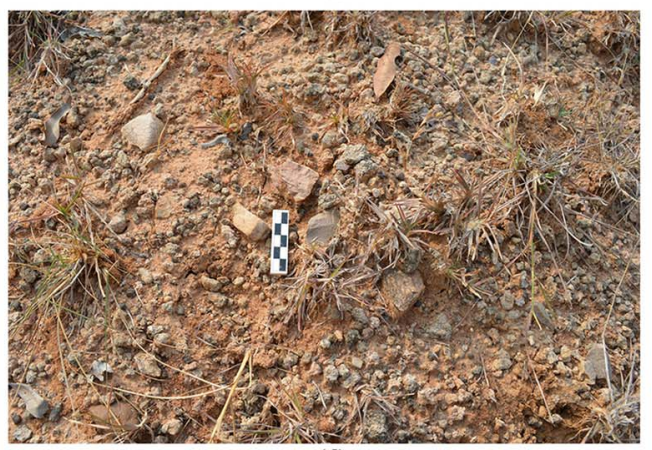

(d)

Figure 4. Artefact distribution within fluvial gravels (site $=$ Goutamnagar $(a-d)$ ).

The presence of stratified Middle Palaeolithic sites, preceded by an Acheulian phase and succeeded by Late Palaeolithic activity, suggests long-term occupation of this landscape. The use of non-local quartzite cobbles in the lithic reduction sequence points to a high degree of mobility across the region and planned site uses. The low level of cortex suggests later stages in the reduction sequence at these sites. The low proportions of Levallois and blades are characteristic of parts of south India (Jayaswal 1974; James \& Petraglia 2009), while the continuity of bifaces is perhaps indicative of the early phases of the Middle Palaeolithic (Akhilesh et al. 2018). These studies highlight regional variability in the Middle Palaeolithic in terms of raw material usage, lithic chaîne opératoire and tool types (e.g. the presence/absence of Levallois, blades, points, tanged artefacts and bifaces) (Haslam et al. 2012; Akhilesh et al. 2018). This variability is significant for the study of local adaptations and regional cultural trajectories, some in a stratified context. The continued presence of bifaces and preference for quartzites in the Middle Palaeolithic, and the early evolution of blade technology, are significant in this respect and are noted elsewhere in India (Akhilesh et al. 2018). The patterns emerging add to the complex nature of regional variability in the Indian Middle 
(a)

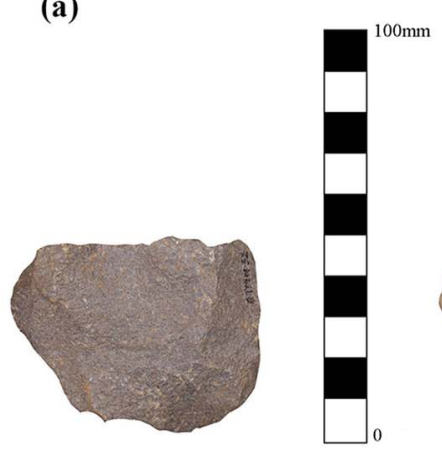

(d)

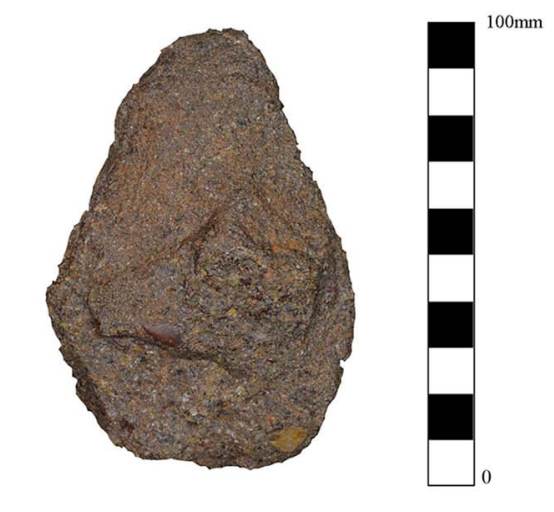

(f)

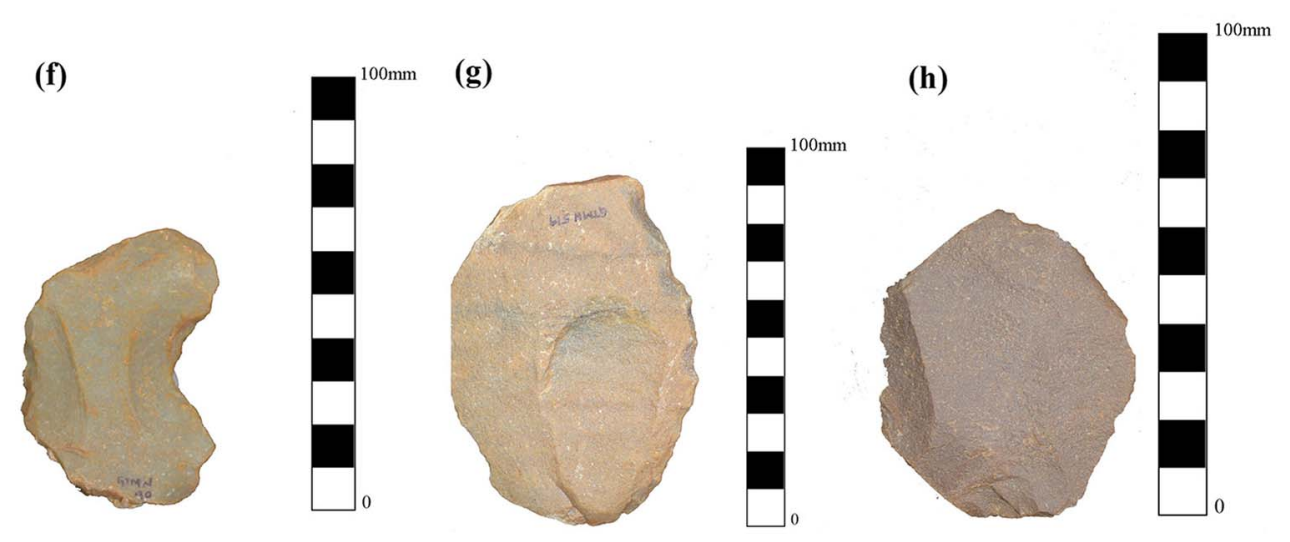

(b)

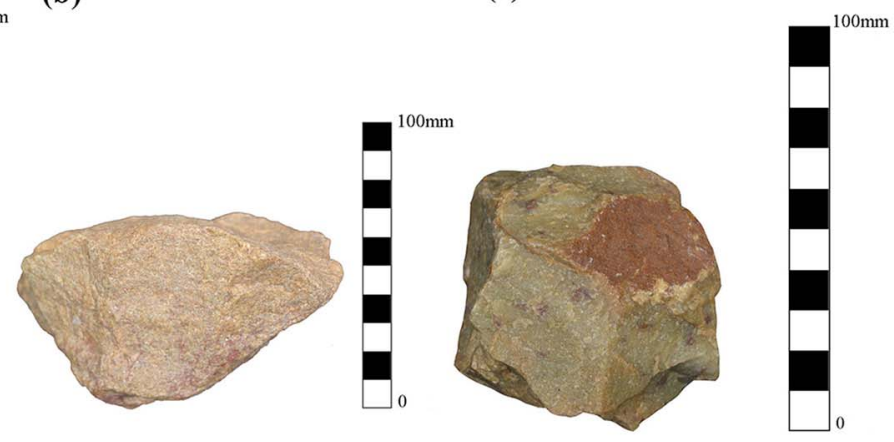

(c)

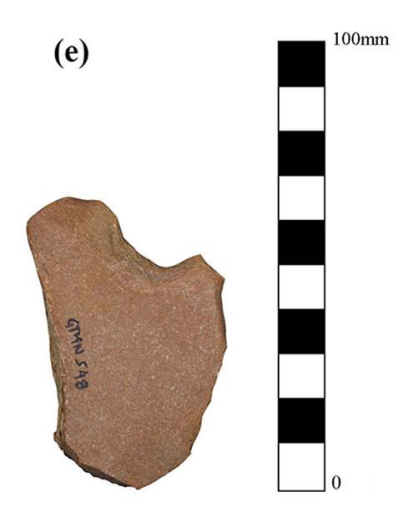

(e)

Figure 5. Middle Palaeolithic artefact types showing: a) preferential Levallois core; b) laminar flake core; c) multidirectional core; d) diminutive handaxe; $e-f$ ) notches; $g-h$ ) scrapers.

Palaeolithic, and serve as a reference point when attempting to demarcate local innovations vs elements that were introduced with dispersing populations (Blinkhorn et al. 2013; Bae et al. 2017).

(C) Antiquity Publications Ltd, 2018 


\section{Acknowledgements}

This research is part of my PhD thesis at Deccan College, supervised by Shanti Pappu and the late M.L.K. Murty, and funded by the Indian Council for Historical Research. I wish to thank S.N. Rajaguru, Kumar Akhilesh, the Sharma Centre for Heritage Education, the Archaeological Survey of India (Hyderabad Circle) and the Department of Heritage Telangana.

\section{References}

Akhilesh, K., S. Pappu, H.M. Rajapara, Y. GunNell, A.D. ShukLa \& A.K. SinghVi. 2018. Early Middle Palaeolithic culture in India around 385-172 ka reframes Out of Africa models. Nature 554: 97-101.

https://doi.org/10.1038/nature25444

Bae, C.J., K. Douka \& M.D. Petraglia. 2017. On the origin of modern humans: Asian perspectives. Science 358: 1-7.

https://doi.org/10.1126/science.aai9067

Blinkhorn, J. \& M. Petraglia. 2017.

Environments and cultural change in the Indian subcontinent: implications for the dispersal of Homo sapiens in the Late Pleistocene. Current Anthropology 58(S17): 463-79.

https://doi.org/10.1086/693462

Blinkhorn, J., H. Achyuthan, M. Petraglia \& P. Ditchfield. 2013. Middle Palaeolithic occupation in the Thar Desert during the Upper Pleistocene: the signature of a modern human exit out of Africa? Quaternary Science Reviews 77: 233-38.

http://dx.doi.org/10.1016/j.quascirev.2013.06. 012

Brooks, A.S., J.E. Yellen, R. Рotts, A.K. Behrensmeyer, A.L. Deino, D.E. Leslie, S.H. Ambrose, J.R. Ferguson, F. D'Errico, A.M. Zipkin, S. Whittaker, J. Post, E.G. Veatch, K. Foecke \& J.B. Clark. 2018. Long-distance stone transport and pigment use in the earliest Middle Stone Age. Science 360: 90-94. https://doi.org/10.1126/science.aao2646

Geological Survey of India. 2002. District resource maps-Adilabad District and Karimnagar District. Kolkata: Geological Survey of India. Haslam, M., C. Clarkson, R.G. Roberts, J. Boro, R. Korisettar, P. Ditchfield, A.R. Chivas, C. Harris, V. Smith, A. Оh, S. Eksambekar, N. Boivin \& M. Petraglia. 2012. A southern Indian Middle Palaeolithic occupation surface sealed by the $74 \mathrm{ka}$ Toba eruption: further evidence from Jwalapuram locality 22.

Quaternary International 258: 148-64. https://doi.org/10.1016/j.quaint.2011.08.040

Hublin, J., A. Ben-Ncer, S.E. Bailey, S.E. Freiduine, S. Neubauer, M.M. Skinner, I. Bergmann, A. Le Cabec, S. Benazzi, K. Harvati \& P. Gunz. 2017. New fossils from Jebel-Irhoud, Morocco and the pan-African origin of Homo sapiens. Nature 546: 289-92. https://doi.org/10.1038/nature22336

James, H. \& M. Petraglia. 2009. The Lower to Middle Paleolithic transition in South Asia and its implications for hominin cognition and dispersals, in M. Camps \& P. Chauhan (ed.) Sourcebook of Paleolithic transitions: methods, theories, and interpretations: 255-64. Dordrecht: Springer.

JAYASWAL, V. 1974. A techno-typological review of the Middle Palaeolithic culture of India.

Puratattva 7: 12-16.

Mishra, S., N. Chauhan \& A.K. Singhvi. 2013. Continuity of microblade technology in the Indian subcontinent since $45 \mathrm{k}$ : implications for the dispersal of modern humans. PloS ONE 8(7): $1-14$. https://doi.org/10.1371/journal.pone.0069280

Petraglia, J., R. Korisettar, N. Boivin, C. Clarkson, P. Ditchfield, S. Jones, J. Koshy, M. Lahr, C. Oppenheimer, D. Pyle, R. Roberts, J. Schwenninger, L. Arnold \& K. White. 2007. Middle Palaeolithic assemblages from the Indian subcontinent before and after the Toba super-eruption. Science 317: 114. https://doi.org/10.1126/science. 1141564

Sсніск, K. 1992. Geoarchaeological analysis of an Acheulian site at Kalambo Falls, Zambia. Geoarchaeology: an International Journal 7: 1-26.

SingH, T.R.R. 1984. Living conditions of Palaeolithic man in Godavari Valley: from Basar to Bhadrachalam. Andhra Pradesh Journal of Archaeology 2(1): 7-29. 